\title{
Daño neurológico central y compromiso isquémico local secundario a inyección de penicilina benzatina
}

\author{
Dr. José Baeza R.; Dr. Jajne Cordero T.; Dr. Adejandro Ríos P.1
}

Central nervous system damage and local isquemic necrosis caused by benzathine penicilin

\begin{abstract}
A seven month old infant suffered convulsions, coma, local necrosis at the site of inyection and at the fourth right toe early after an intragluteal injection of $400.000 \mathrm{U}$ of Benzathine Penicilin that was given for a mild upper respiratory infection. Late scquelae included loss of the affected toe, retarded psicomotor development and generalized muscular hypertony that was more severe in the lower extremities. These complications were probably caused by inadvertent intraarterial injection of the compound. Infants are at increased risk because they have less developed muscular mass. Benzathine Penicillin is seldom, if ever, justified in the treatment of upper respiratory infections in infants and the best management for the described complications in this age group is avoidance of its unnecessary use.
\end{abstract}

(Key words: Benzathine Penicillin, local and distal necrosis, central nervous system damage, accidental intráterial injection).

La administración intramuscular de penicilinas de acción prolongada (Penícilina G. Benzatina Penicilina Procaína), solas o en combinación, constituyen una práctica frecuente en pediatría.

En muchos casos, especialmente en niños me. nores, dicha indicación carece de claros fundamentos clínicos y bacteriologicos, sometiendo a los pacientes a una experiencia dolorosa injustificada y no exenta de riesgo. Además del peligro de reacciones de hipersensibilidad que son inherentes al uso de cualquier tipo de penicilina, ${ }^{1}$ las de acción prolongada han sido señaladas como causa de daño local con producción de lesio. nes isquémicas que ocasionan desde pérdidas mínimas de piel a necrosis de ortejos con amputación $^{2}$ y déficits neurológicos de extremidades como paresias o parálisis. ${ }^{3,4}$

Dado el amplio uso de estos medicamentos en nuestro medio, consideramos necesario alertar sobre este tipo de complicaciones que general. mente no son valoradas dentro del amplio contexto riesgo beneficio que involucra toda indica. ción terapéutica, a propósito de un lactante menor quién, en relación con el uso intramuscu. lar en la región glúntea de penicilina benzatina, desarrolló lesiones isquémicas con necrosis de la región glútea y de un ortejo, junto con compromiso neurológico central.

1. Unidad de tratamiento intensivo. Hospital Luis Calvo Mackenna.

\section{Caso Clínico}

Lactante de 7 meses de edad que recibió 400.000 unidades de penicilina benzatina en el cuadrante superior externo del glúteo derecho, indicado por una "faringitis aguda". Pocos minutos después de la inyección presentó compromiso de conciencia, palidez, hipotonía y alteraciones de coloración en el hemicuerpo inferior (áreas de cianosis marmórea y blanqueamiento). Ingresó al servicio de urgencia, donde se pensó inicialmente en "shock" anafiláctioo y se administró adrenalina, esteroides y antihistamínicos. Sus condiciones clínicas no mejoraron, perzistiendo compromiso neurológico que se complicó en las horas siguientes con convulsiones tónico clónicas generalizadas: la primera de ellas, con bradicardia extrema, requirió maniobras de reanimación. Las lesiones en hemicuerpo inferior se acentuaron en la zona glútea puncionada y la extremidad inferior ipsilateral. Un examen con Doppler mostró indemnidad de los pulsos arteriales, femorales $y$ pedios. El líquido cefalorraquídeo (LCR), las pruebas de coagulación, glicemia, electrolitos plasmáticos y hematocrito no mostraron anormalidades. Se planteó el diagnóstico de tromboembolismo secundario a vasculitis e inició tratamiento con heparina (6 mg $\mathrm{c} / 6 \mathrm{~h}$ e.v.), plasma fresco, esteroides (hidrocortisona $100 \mathrm{mg} \mathrm{c} / 6 \mathrm{~h}$ e.v.). Ante la falta de respuesta fue trasladado a la unidad de cuidados intensivos, 48 horas des. 
pués de iniciados los síntomas descritos, con evidente compromiso neurológico central, muy irritado, desconectado del medio, hipoactivo, con sólo respuesta flexora a los estímulos dolorosos.

En el sitio de la inyección existía una extensa y profunda zona de necrosis claramente delimitada (figura 1), la extremidad inferior derecha estaba edematosa, sensibie y tenía zonas de coloración rojo violácea reticulares, especialmente en dorso y región plantar del pie, con cianosis y enfriamiento del cuarto ortejo (figura 2). Existian alteraciones similares, menos acentuadas $y$ numerosas, en la extremidad inferior contralateral, genitales externos, glúteo izquierdo e hipogastrio derecho. Los reflejos en las extremidades inferiores estaban exagerados.

Una nuewa serie de exămenes de LCR, plaquetas, N.ureico, coagulación y cultivos de san. gre, orina, fueron normales. Las pruebas hepáticas mostraron discreto $y$ transitorio aumento de las transaminasas, que fue atribuido a necrosis muscular.

El paciente requirió 45 dias de hospitaliza. ción, evolucionando febril durante la primera semana, sin que se demostrasen focos infecciosos. Repitio en 3 oportunidades las convulsiones $y$ persistentemente presentó descargas mioclónicas, a pesar del tratamiento con drogas anticonvulsi. vantes. La tomografía cerebral no reveló signos de isquemia ni lesiones vasculares trombóticas o embólicas. El EEG mostró signos lentos difusos con lateralización en hemisferio izquierdo. Las lesiones isquémicas locales aumentaron en la zona glútea derecha hasta producirse necrosis de la picl $y$ los músculos que hicieron necesario realizar escarectomía e injertos diferidos. La falange distal del $4^{\circ}$ ortejo se perdió por necrosis.

Controlado dos meses después de su alta, habia mejorado parcialmente del daño neurológico: se encontraba sin actividad convulsiva con mejor grado de relación con el medio, pero persistía la hipertonia generalizada más acentuada en las extremidades izquierdas.

\section{COMENTARIO}

Los peligros de la administración intramuscular de medicamentos en la región glútea han sido reconocidos desde muy antiguo, ${ }^{5,6}$ Sintomas locales similares a los presentados en nuestro paciente fueron descritos hace 60 años en relación con el uso de preparados de bismuto y mercurio para el tratamiento de la sifilis.

El primer informe que involucra a las penici. linas de acción prolongada data de $1966^{7}$ y desde entonces han sido publicados numerosos casos (tabla).

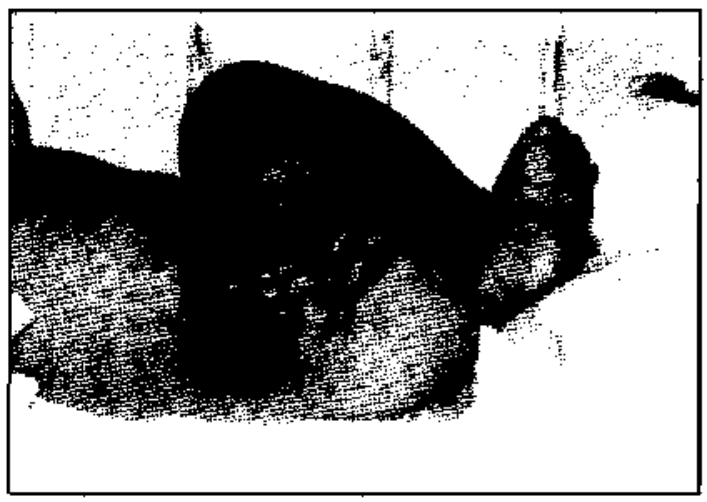

Figura 1: Necrosis extensa y profunda del sitio de la inyección de $\mathbf{4 0 0} 000 \mathrm{U}$ de penicilina benzatina en un lactante de 7 meses.

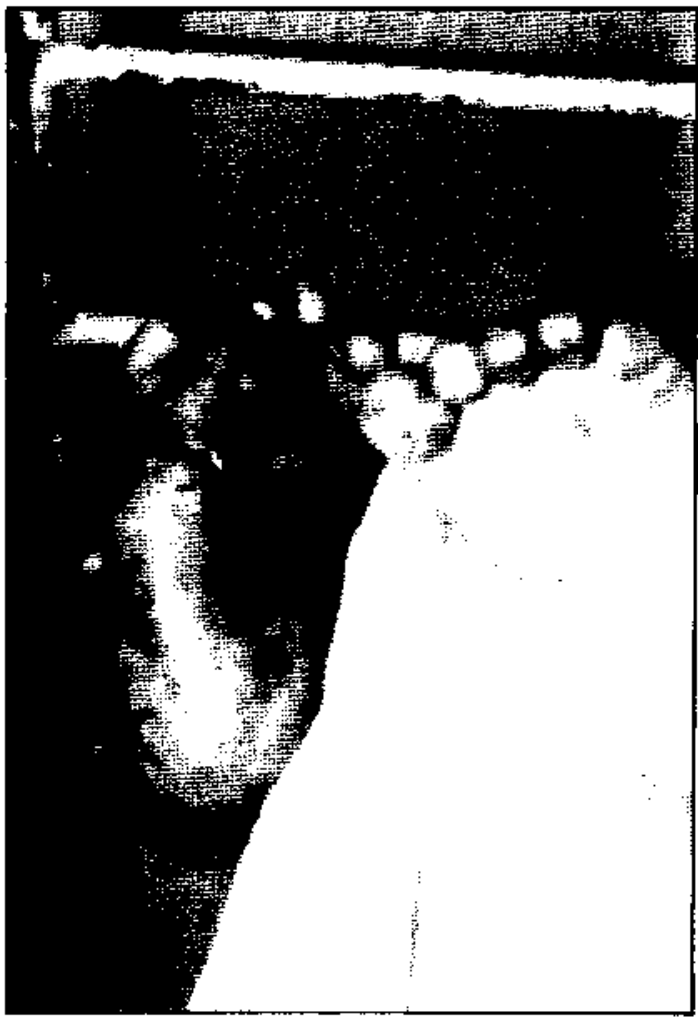

Figura 2: lidema, enrojocimiento plantar y necrosis del $4^{\circ}$ ortejo del pie derecho en el mismo paciente de la figura $]$.

En los niños en que se utiliza la región glútea y el muslo como sitios preferidos de inyección intrarnuscular, la presentación de esta complicación está confinada al grupo menor de tres años y especialmente a los lactantes, a semejanza de lo que ocurre con las injurias directas al nervio ciático. ${ }^{10}$

Los síntomas y signos que se describen son similares en todos los pacientes y corresponden a isquemia aguda severa. Esta se manifiesta casi 
Tabla

Inyeción intraarterial inadvertida de penicilina de acción prolongada.

Resumen de los casos publicados

\begin{tabular}{|c|c|c|c|c|c|c|}
\hline Autor & Año & $\begin{array}{l}\text { Ead del } \\
\text { paciente } \\
\text { (mes) }\end{array}$ & $\begin{array}{l}\text { Sitio do } \\
\text { inyección }\end{array}$ & $\begin{array}{l}\text { Medicamento } \\
\text { usado }\end{array}$ & $\begin{array}{l}\text { Destino } \\
\text { final } \\
\text { Jesión }\end{array}$ & $\begin{array}{l}\text { Tratamiento } \\
\text { empleado }\end{array}$ \\
\hline $\begin{array}{l}\text { Knowiles } \\
(7)\end{array}$ & 1966 & $2 \mathrm{ml}$ & Glúteo & $\begin{array}{l}\text { Benzatina } \\
\text { Protainat }\end{array}$ & $\begin{array}{l}\text { Necrosis glútea } \\
\text { hemipatesia } \\
\text { ext. int. izq. * }\end{array}$ & $\begin{array}{l}\text { Anestesia } \\
\text { espinal }\end{array}$ \\
\hline \multirow[t]{2}{*}{$\begin{array}{l}\text { Shaw } \\
(3)\end{array}$} & 1966 & $15 \mathrm{~m}$ & Gúteo & $\begin{array}{l}\text { Benzatina } \\
\text { Procaina }\end{array}$ & $\begin{array}{l}\text { Mielitis trans- } \\
\text { versa. Paraplejia }\end{array}$ & $\begin{array}{l}\text { Esteroide } \\
\text { acido } \\
\text { nicotínico }\end{array}$ \\
\hline & 1966 & $36 \mathrm{~m}$ & Glúteo & $\begin{array}{l}\text { Benzatina } \\
\text { Procaína }\end{array}$ & $\begin{array}{l}\text { Regresión } \\
\text { lesjones isquém. } \\
\text { sin secuelas }\end{array}$ & $\begin{array}{l}\text { Anestesia gene- } \\
\text { tal, bloqueo } \\
\text { simpático }\end{array}$ \\
\hline $\begin{array}{l}\text { Atkinson } \\
\text { (4) }\end{array}$ & 1569 & $7 \mathrm{~m}$ & Glúteo & $\begin{array}{l}\text { Benzatina } \\
\text { Proca ina }\end{array}$ & $\begin{array}{l}\text { Necrosjs cu tánea } \\
\text { Paraplejia }\end{array}$ & No consignado \\
\hline $\begin{array}{c}\text { Daslyy } \\
(8)\end{array}$ & 1973 & $12 \mathrm{~m}$ & Gisteo & $\begin{array}{l}\text { Bematina } \\
\text { Procaina } \\
\text { Potásica }\end{array}$ & $\begin{array}{l}\text { Netrosis glútea } \\
\text { y dorso del pie } \\
\text { hemiparesia } \\
\text { transitoria }\end{array}$ & $\begin{array}{l}\text { Anestesia } \\
\text { espinal }\end{array}$ \\
\hline \multirow[t]{2}{*}{ Schanzer } & 1979 & $10 \mathrm{~m}$ & Muslo & $\begin{array}{l}\text { Benzatina } \\
\text { Procaina }\end{array}$ & $\begin{array}{l}\text { Regresión } \\
\text { lesiones } \\
\text { sin secuelas }\end{array}$ & Sin tratamiento \\
\hline & 1979 & $36 \mathrm{~m}$ & Muslo & $\begin{array}{l}\text { Benzatina } \\
\text { Procaina }\end{array}$ & $\begin{array}{l}\text { Amputación } 1^{a} y \\
2^{a} \text { falange pie } \\
\text { Limitación mov." } \\
\text { ex tromidad inf." }\end{array}$ & $\begin{array}{l}\text { Heparina } \\
\text { Fasciotomía }\end{array}$ \\
\hline $\begin{array}{c}\text { Bravo } \\
(9)\end{array}$ & 1983 & 32 años & Brazo & Benzatuna & $\begin{array}{l}\text { Necrosis cutánea } \\
\text { Limitación mor." } \\
\text { de la mano }\end{array}$ & $\begin{array}{l}\text { Reserpina in- } \\
\text { traarterial } \\
\text { Heparina }\end{array}$ \\
\hline $\begin{array}{l}\text { Stolliar } \\
(10)\end{array}$ & 1985 & 4131 & Muslo & Benzatina & Daīo ep ífisis & No consignado \\
\hline
\end{tabular}

*A breviaturas: ext. = extromidad; inf. $=$ inferior $;$ izq, $=$ izquirada (o); mov. = movimiento; isquem. =isquémico (a)

inmediatamente después de la inyección del medicamento, en forma de cambios de coloración, enfriamiento e impotencia funcional de la extremidad comprometida. Inicialmente algunos autores sostuvieron que ella era provocada por vasoespasmo inducido por depósito de material inyectado en la vecindad de un vaso arterial importante. ${ }^{8}$ Sin embargo, un reciente estudio experimental utilizando la mezcla de benzatinaprocaina ha demostrado que este tipo de accictente es ocasionado por inyección intraarterial. ${ }^{11}$

La extensión de las lesiones alejadas del sitio de punción guarda directa relación con el territorio de irrigación đe la arteria comprometida. A partir del yaso principal el medicamento depositado es distribuido por la corriente sanguínea, ocasionando oclusión embólica o daño endot elial y trombosis del territorio distal arteriocapilar, produciendo severa disminución de la perfusión y el consecuente daño tisular.
Los déficits neurológicos asociados se explican también por compromiso isquémico del nervio ciático. En los casos de mielitis transversa se presupone que las partículas de benzatina inyectadas bajo alta presión en la arteria glútea alcanzan por flujo retrógrado (vía arteria ilíaca interja) los vasos que irrigan la médula espinal. ${ }^{4,7}$ Por estar comprometido sólo el territorio arteriolar y capilar, los pacientes conservan los pulsos de las grandes arterias y en los casos en que se ha efectuado arteriografia no se encontraron anormalidades. ${ }^{8}$ De mayor utilidad en esta situación sería el uso de la pletismografía y la radiografía isotópica. ${ }^{9}$

En la literatura revisada no encontramos referencias al compromiso del sistema nervioso central. Aunque no tenemos una explicación para to observado en nuestro paciente, sus manifestaciones $y$ las secuelas posteriores estan en evidente relación con la administración intraarterial de la 
penicilina benzatina, descartándose razonablemente, a través de los exámenes practicados, otra etiologia. Una vez producido el accidente, sc han recomendado diversos medicamentos para evitar el desarrollo de las lesiones isquémicas (anestesia espinal con bloqueo simpático, anestesia local, esteroides, ácido nicotínico, vasodilatadores), pero la diversidad de tratamientos empleados y la existencia de casos con remisión espontánea, hacen dificil valorar su efectividad. En consideración a la patogenia, es más probable que la magnitud del daño dependa de la cantidad de material inyectado $y$ de su efecto inicial que de las medidas terapéuticas posteriores.

Las desastrosas consecuencias provocadas por el depósito intraarterial de estos medicamentos, no pueden ser atribuidas a simple error en escoger el sitio de punción o a la falla en aspirar para detectar reflujo de sangre antes de inyectar. En la mayoría de los casos publicados, el lugar de punción ha sido el adecuado y la aspiración previa negativa. Excluyendo, por tanto, inexperiencia o negligencia en la técrica, dos factores serian importantes para que se produzcan accidentes de este tipo: el tamaño de la masa muscular escogida para inyectar y la viscosidad de la preparación empleada. A diferencia de los niños mayores que alcanzan un desarrollo muscular adecuado de los glúteos después de la deambulación, en los lactantes esta zona se caracteriza por ser pequeña y estar constituida sobre todo por tejido graso. ${ }^{12}$ situación que favorecería las injurias directas del nervio ciático o sus ramas ${ }^{15} \mathrm{y}$ también el daño vascular. Para cuitarlas muchos autores ${ }^{7}, 8,10,12$ han preconizado el emplco, para tratemicnto intramuscular a estas cdades, del cuadrante supero externo del muslo. Et cuadriceps femoral, el mayor músculo del cuerpo humano, ya posec una masa relativamente grande al nacer, ${ }^{12}$ los vasos y nervios mayores están prof undamente situados, $y$ asi, más protegidos de la punción. Esta práctica si bien evita las injurias neuronales directas o indirectas (por isquemia) y disminuye la posibilidad de punción arterial, no la excluye totalmente, como lo confirman los casos cn los cuales el sitio puncionado ha sido el muslo. 2.10 .13

EI segundo factor predisponente de esta complicación está relacionado con las caracteristicas físicoquímicas de los preparados de benzatina: su alta viscosidad y la opacidad de los dispositivos que la contienen, a diferencia de los productos translúcidos para uso intramuscular, obstaculizan la percepción det reflujo de sangre si se ha puncionado un vaso arterial. ${ }^{10.14}$ Esta situación ha motivado urgentes sugerencias a los productores para que cambien los dispositivos que actualmente se utilizan. Aún así, es probable que a pesar de una técnica adecuada y del empleo de dispositivos modificados, el accidente continúe presentándose. Si recordamos lo difícil que es asegurar la inmovilización en niños menores, comprenderemos que bastaría un pequeño movimiento para que todas las precauciones fracasen y la aguja correctamente introducida se desplace hacia un vaso arterial o produzca daño neuronal.

Como las complicaciones relatadas afectan al grupo menor de dos años, la mejor prevención consistirá en racionalizar el uso de estos preparados limitándolo a los pocos casos en que realmente se justifica. El uso indiscriminado de penicilina benzatina, procaina o ambas, para infecciones faringoamigdalianas o de vías respiratorias superiores no bacterianas, a esta edad, es una práctica que debe abandonarse, porque no se fundamenta en bases bacteriológicas claras ${ }^{16}$ y exponen a las devastadoras consecuencias de daño vascular con gangrena, amputación o pará. lisis.

\section{RESUMEN}

Un lactante menor de 7 meses de edad, a consecucncia de la inyección intraarterial inadvertida de penicilina benzatina en la región glútea, la que fue indicada por un diagnóstico de faringitis, sufrió compromiso neurológico central y lesiones isquémicas con necrosis glútea y pérdida de un ortejo. La frecuencia de casos similarcs reportados ha aumentado en la literatura. Este tipo de complicación se observa casi exclusiva. mente on niños menores de 3 años y ocurre a pesar de emplear una técnica correcta de pun. ción. Ante la falta de tratamiento satisfactorio, el mejor manejo de este tipo de accidentes es la prevención, mediante la racionalización del uso de estos preparados, prescribiéndolos sólo cuando su empleo está plenamente justificado.

\section{REFERENCIAS}

1. Sher Theodore H.: Penicillin Hypersconsituvity - A Review. Pediatr Clin North An 30: 16I, 1983.

2. Schanzer H., Gribetz 1., Jacobson II J.H. -Accidental intraarterial injection of Pencílin G.A. Preventable catastrophe. J A M A 242: 1289, 1979.

3. Shaw E.B.: Transverse myelitis from injection of penicillin. Am J Dis Child l 11: 552, 1966.

4. Atkinson J.P.: Transwerse myel opathy secundary to injection Penicillin. J Pediatr 75:867, 1969.

5. Nicholat $S$ : Dermite liveloide el gangreneuse de la fissc, consccutive aux injections intra-musculaires, dans la syphilis: a propos dun cas d'enbolic arteridle bismuthique. Ann Mal $\mathrm{V}$ en 20:321, 1925.

6. Gommal J.A.: Arterial embolistr: an unusual complication following the intramuscular administration of Bismu th. J A M A 88: 998, 1927.

7. Knowles J.A.: Accidental intra-arterial injection of penicillin. Am J Dis Child 3: 553, 1966. 
8. Darby C.P., Bradham G., Woller C.E.: Ischemia following an intragluteal injection of Benzathineprocaine penicilin $G$. Mixture in a 1 year old boy. Clin Pediatr 12: 485, 1973.

9. Bravo M., Naranjo L.: Insuficiencia Arterial Aguda por inyección intraarterial de Penicilina Berzatina. Rev Chil Cit 35: 446, 1983.

10. Stoller $K . P_{*}$, Losey $R$. . Inadvertent intra-arterial injection of Penicillin; An unseen Danger. Pediatrics 75: 785,1985 .

11. Schonzer H., Jacobson $/ I$ J.H. Tissue Damage caused by the intramuscular injection of long-acting Penicillin. Pediatrics 75: 741, 1985.
12. Bergeson P.S., Singer S.A., Kaplan A.M.: Intramuscular injection in children. Pediatrics $70: 944,1982$.

13. Talbert J.L., Hatlam R.H.A.. Haller J,A.: Gangrene of the foot following intramuscular injection in the lateral thigh: A care report with recommendations for prevention, J Pediatr 70: 110, 1967.

14. Col Michael R.W.: Intramuscular Penicillin. Pediatries 77: 783, 1986

15. Brandt P.A., Smilh M.E., Ashburn S.S et al: Injections in children, An $J$ Nurs 72: 1402, 1972.

16. Alpert J.J., Pickering M.R. Warren R.J.: Failure to isolate streptococi from children under the age of 3 years with exudative tonsillitis. Pedjatrics 38 : $663,1966$. 